\title{
Exploring working places and self-generated learning spaces: concepts, perspectives and cases from the United Kingdom
}

\author{
Natasha Kersh and Karen Evans
}

The article focuses on the notion of the learning space at work, particularly considering the relationships between work, learning, human agency and space. The issue of recognising working spaces as contexts for learning has received much attention in the educational debates of the past twenty years across a number of countries worldwide, and in particular, in Asia and Europe (Chisholm et al, 2012). The interpretation of the workplace as a site only for work and job-specific training has been changing, and workplaces are now being acknowledged as sites for learning in various configurations. The article draws on the notion of the learning spaces at work, looking specifically at their structure, meaning and affordances in different settings. In order to explore ways in which workplaces are experienced as learning spaces the study employs the photo-participatory method. The method has enabled practitioners to articulate what a learning space means for them, in ways that contribute to both visualization and reflection. The cases, considered in this article, demonstrate the way individuals construct their own working spaces, discussing their particular strengths and limitations. The research has suggested that different types of learning spaces (such as institutional or independent sector settings) may play a significant part in enhancing the learning processes, motivations and attitudes of employees within their workplaces. The article considers views and perspectives from both independent specialists and institutional teachers and researchers specifically reflecting on how the concept of space influences their professional and personal development as well as life chances within the workplace and beyond.

Key words: learning space, workplace, self-generated learning spaces, photoparticipatory method 


\section{Introduction}

The notion of the 'learning space' and its different meanings and implications has been discussed extensively in a range of research publications (e.g. Brooks et al, 2012; Chisholm et al, 2012; Evans and Kersh, 2014). The interplay between spaces and learning has received recognition as one of the fundamental aspects of the debate on contemporary workplace learning and competence development (Evans and Kersh, 2017; Brooks et al, 2012). Factors such as the rapid expansion of digital technologies, the recognition of the significance of different modes of informal learning and globalisation have had a profound impact on the perception of the learning space, its purposes, meanings and implications. The perception of the learning space as a conventional physical space has changed, and learning spaces stretch beyond classrooms and teaching spaces. As Brooks et al (2012) note, this trend has been associated with the shift away from an objective understanding of space as a system of organisation or geometry towards an emphasis on how space is constructed through the social processes that give it meaning.

The concept of space as a configuration of an environment or a context has interdisciplinary significance. The conception of space that originated from the discipline of geography has recently received substantial attention from other disciplines, and in particular from the social sciences. This trend has been characterised by the shift away from an objective understanding of space as a system of organisation or geometry towards an emphasis on how space is constructed through the social processes that give it meaning where learning spaces at work are not just containers of moveable objects and dynamic flows of behaviour (see Brooks et $\mathrm{al}, 2012$ ). Spatial theories seek to provide a relational understanding of how these spaces are constituted and how they are given meaning through human action.

A range of studies addressing the relationship between power and knowledge has highlighted the importance of relationships of space to societies as well as spacetime relationships (e.g. Foucault, 1980; Soja, 2002; Goffman, 1990). In exploring the notion of space, social sciences research largely focuses on the ways space is constructed through social processes and constructed by them (Brooks et al, 2012). Employees' personal workspaces enhance their effectiveness, creativity and social practices, within constantly changing contemporary workplaces (Kohlegger et al, 2013).

The issue of recognising working spaces as contexts for learning contexts has received much attention in the educational debates of the past twenty years, and especially during the most recent decade across a number of countries worldwide, and in particular, in Asia and Europe (Chisholm et al, 2012). The role of learning spaces for lifelong learning specifically in relation to the education of adults has been and remains one of the central points of this debate. A significant body of 
research literature (e.g. Edwards, 2006; Evans et al 2006; Malloch et al, 2011) brings attention to the significance of the workplace context and the distinctive features associated with learning within a working space, and its impact on individual motivations, experiences and outcomes. As earlier suggested in the 1995 research by Nonaka and Takeuchi, shared mental models at work relate to shared space within, and this provide opportunities for learning, knowledge sharing and linking practice and context within social situations (Nonaka and Takeuchi, 1995). What employees learn as 'learners in the workplace' and in experiences beyond the workplace (Livingstone, 2006) leads to the development of new forms of knowledge and competence.

\section{Working places as learning spaces: conceptual issues}

The perception of the workplace as a site only for work and organisation-specific training is gradually changing, as workplaces are now being acknowledged as sites for learning in various configurations, contributing to lifelong learning, personal development and social engagement of individuals (Fuller et al, 2007; Heiskanen and Heiskanen, 2011; Guile, 2010a), as well as the exercise of wider social responsibility in and through learning (Evans, 2009). The traditional model of workbased learning was the 'one-off, pre-service education and training model' (Hodkinson and Bloomer, 2002). Thus, as noted by Evans and Kersh (2014), the traditional view of work-based learning was that it mainly consisted of qualifications or training (such as the apprenticeship model) gained prior to employment or progression in employment. This model is being challenged by the interest in 'workforce development' and the changes in the perceptions of learning spaces at work. Evans et al (2006) distinguish between workplace training and learning by making a point that training implies an intervention that is formally structured and involves a transfer of a body of knowledge, while workplace learning is more encompassing and involves locating learning in social relations at work (Evans et al, 2006). Workplace learning could be further facilitated within a learning organisation, through a range of approaches, for example mentorship (Chen and Wen, 2011), an innovative apprenticeship model (Rauner et al, Guile, 2010b) or a model of lifeplace learning that is associated with the model for creating new structures for accreditation of prior learning through reflective practice (Harris and Chisholm, 2011). Remedios and Boreham (2004) note that a necessary feature for an organisation to label itself a learning one is that mechanisms are put in place to optimise the transfer of knowledge between all levels of employees thus creating an environment where employees recognise that their ideas will be acknowledged, 
discussed and can influence subsequent working procedures. Workplace spaces are then characterised by being both work and learning spaces where the boundaries between the two are considerably blurred (Solomon et al, 2006: 6). As Brooks et al note, it has, in some sense, been driven by contemporary policy initiatives: the encouragement for us all to contribute to learning throughout our lives, to ensure we stay employable in a constantly changing globalized competitive environment (Brooks et al, 2012).

Previous research (e.g. Evans et al, 2006; Solomon et al, 2006; Kersh et al, 2011) has indicated that the concept of the learning space can be considered from various angles and perspectives. Firstly, the learning space can be perceived as a physical space where learning is taking place such as a classroom or any other form of teaching space. Secondly, the learning space can refer to a space where learning occurs unintentionally, as informal learning, for example at work where employees learn from each other's experiences. Thirdly, the recent expansion of digital technologies has resulted in the development and growth of virtual learning spaces that ultimately change the boundaries of learning spaces making them more flexible and mobile. Finally, the learning space can be perceived as a combination or overlap of a range of components, such as physical space, learning contexts and environments, formal/informal learning and virtual learning. Recent trends in economic, political and educational developments have resulted in somewhat blurred boundaries between the spaces in which learning, work and leisure occur.

Situated learning theory further enriches the concept of the learning space by reminding us that learning spaces extend beyond the teacher and the classroom (Kolb and Kolb, 2005). Solomon et al (2006) draw on the term 'workplace learning', arguing that this notion has particular meanings and practices because of its location and because that location is not an educational institution. Drawing on the work of Bronfenbrenner (1977; 1979), Kolb and Kolb (2005) refer to four types of learning space. The learner's immediate setting, such as a course or classroom, is defined as the microsystem. The 2012 research by Kersh et al (2012) has also extended the concept of the microsystem to the learner's immediate workplace setting since we consider workplaces as learning sites. Other concurrent settings in a person's life such as other courses or family are called the mesosystem. The exosystem refers to the formal and informal social structures that influence the learner's immediate environment, for example, institutional policies and procedures and culture. Finally, the macrosystem relates to the overarching institutional patterns and values of the wider culture, such as cultural values favouring abstract knowledge over practical knowledge, which influence actors in the person's immediate microsystem and mesosystem. Correspondingly, the formulation of workplace learning by Evans et al. (2006) emphasises individual, institutional and 
environmental scales of learning at work, understood as learning that happens in, for, and through the workplace.

Interviews undertaken as part of the ASEM Lifelong Learning Hub study have used the photo-participatory method with the aim of uncovering how individuals experience and create their learning spaces both within and outside their workplace settings. Our respondents included:

- Independent information technology (IT) specialists

- Institutional IT teachers

- Academics and researchers working with IT resources.

Practitioners were invited to participate in the study by taking photographs of scenarios or images that captured, for them, their learning space. Their explanations of their learning spaces have, with consent for their use, provided material for the cases discussed in this article.

Including the perspectives of independent specialists as well as institutional teachers and researchers has enabled us to shed light on how learning spaces are understood and negotiated in both institutional and independent workplace modes and settings. The cases considered below demonstrate the ways that learning spaces are perceived, constructed and co-constructed through a range of contexts and environments.

\section{Working spaces: self-created learning spaces}

The configurations of different types of learning spaces in the contemporary world have resulted in the emergence of what Felstead and Jewson (2012) referred to as new places of work and new spaces, such as collective offices and new work locations (such as at home and on the move). They further note that the trend is not for work simply to shift from one type of workplace to another but rather to spread out across a diverse network of different sites, which are linked by information and communications technology (Felstead and Jewson, 2012: 154). One significant implication of the individual scale of learning spaces at work is associated with the way individuals create or construct their own personal spaces which enables them to engage in their workplace activities. The cases below demonstrate the way individuals construct their own working spaces, discussing their particular strengths and limitations. 
Case 1. Self-Created learning spaces: perspectives from an independent IT consultant.

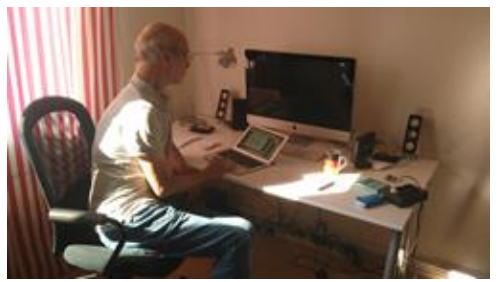

I work for a small research and development company [...] registered [...] in Wales. We have something like 14 employees, most of us part time, and living in Wales, England, Germany and Spain. Although we have two offices, in Pontypridd and in Bremen, Germany, most of us work from home. We make extensive use of technologies for day to day communication. I have two of what the Germans call 'home offices' in my two homes in Spain and Germany. I suppose these are the nearest I have to a 'traditional' working space.

The offices serve a number of purposes. One of the big advantages of working from home is that it does not take long to get to work (in one of my previous jobs I was traveling nearly three hours every day, to and from my official workplace). But there are downsides. One is that I am not careful I can end up working very long hours - another is that it is hard to get away from the work. At least with an office it is possible to escape form the clutter of work instruments and tools - papers, files, computer equipment, printers, stationary and so on. Secondly, the office provides a place to flee to avoid disturbing other people in my flat. Neither office is really idealnor am I quite sure what an ideal office would look like. Certainly in summer both suffer from a surfeit of sunlight! But at least in my larger [...] office, I have an old sofa and an Ikea chair for when I get fed up at sitting at the desk. The big problem with an office I think - and this applies just as much if not more to working in an institutional environment - is social isolation. I used to work in an institution in the university in Bremen. It was a modern architect designed, environmentally friendly building. It certainly was not the breeze blog and concrete UK researchers have had to get used to. And in terms of learning probably one of the worst places I have worked. The blinds went up and down automatically according the not so intelligent decisions of the central computer. Lights were automatic too. In evenings if you did not move enough you were plunged into darkness. But worst was that although everyone had very nice offices, the building had been designed without any social spaces (apart from two small kitchens). And it is in those (informal) social spaces where learning takes place.

There are similar downsides to working at home despite the ease of telecommunications. But I frequently move around the flat to different rooms and there is usually some kind of everyday social interaction, certainly with the environment, often with other people. 
Case 2. Perspective from an Information Technology college tutor: creating personal spaces through sharing and interacting with colleagues.

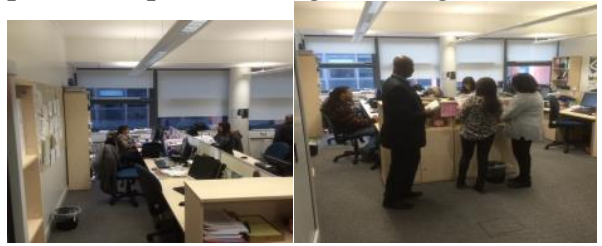

There's been plenty of interaction with other people in the department, like sitting next to me, I'll just hand them my materials, and I don't get a lot back but I get some back! But I guess that's just the way it is, I tend to be a person who creates lots and lots of [teaching] materials anyway [...]. But having said that, that makes me popular with my other colleagues because straightaway they've got, made up sessions, if they're teaching the same topics, the same unit, I tend to be first port of call. [...] So from that viewpoint, that type of working space does function extremely well. It's only when you need that quiet time, that time when you really have to focus on what you're doing, is undoable, absolutely undoable. Now that environment there $[\ldots]$ is just 3 desks, 3 desks, 3 desks, 3 desks. 1,2,3; 1,2,3; a computer, you know you use the little drawers and so forth, and as I say the strengths are that it's good from the viewpoint of, as I say, interaction with colleagues, and so therefore it does enforce a sharing situation from both work prospect and also we share materials, we share resources, we share knowledge quite freely in my department. I've been trying to do something with another colleague on games design and so been looking at this particular software that the client happens to have online, which is challenging software at best, but he's helping me and I'm helping him, so there is a good - and he sits next to me, so it works extremely well from that viewpoint. It's crucial in a sense because, when you're working you need to have your things that you know, that are familiar. [...] I've got my hard drives there [in my working space], I've got a drawer full of old CDs and stuff that I might want to access and other bits and pieces, somewhere to put your bag[...], I mean it's just little things like that when you arrive. But an area to be able to put your day to day and week to week paperwork that you know you're going to need, and a little space at the back there where you can pin your timetable, you can pin your meeting timetable, you can pin any of the student related [notes]...where external people are coming in and all that, sort of your dates and so forth, your calendars. So if you've got that information just there it's very, very crucial. And behind me we've got the student timetables, well the teaching timetables of each group, so I can just turn round and go 'OK I know where my colleagues are'. 
Case 3. Perspectives from a university researcher: New learning spaces: 'The bus - where I could fit it in'.

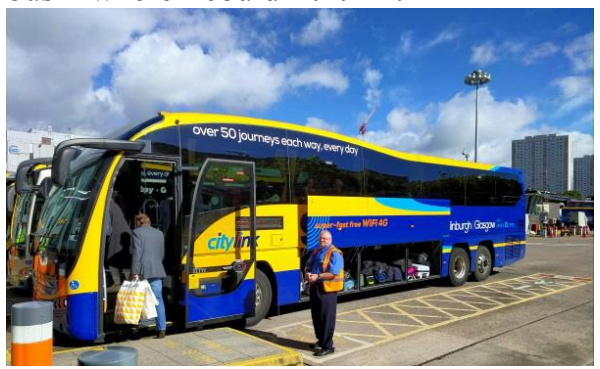

Most of my doctoral thesis was written on the No 17 bus between Byres Rd in Glasgow and Paisley. My funding had finished and I was working creating distance learning materials at the University. I'd print out the current draft of a chapter each night, edit and expand on it on the bus journeys that day then slink into the lab late at night to use the PC to type things up and print something else to work on the next day. The key here, is that while the physical space on a bus is never ideal, it worked for me because it was a regular time (10 times a week, for 40 minutes) when I could immerse myself in writing up that didn't get in the way of my new work responsibilities. Bus journeys have always been a key learning space: after I left Paisley, I spent five years commuting to Heriot-Watt and read for a couple of hours on the bus everyday during that time. I've also spent a lot of my life living and working between Glasgow and Edinburgh regularly 'crossing Scotland's waist'on the No. 500 bus - giving me even more time to read and learn. I'm ashamed to say that I read much less nowadays and I've always maintained that during that time I got out of the habit of reading at other times when I had so much time to read on buses. Now my commute is car and bike based, so reading isn't an option, but I routinely use my commuting time at each end of the working day to plan and reflect.

The interpretation of these cases indicates the interplay between the three dimensions of the learning space, namely individual, environmental and institutional. The individual dimension plays a central role in the development of personalised self-created learning and working spaces. The three cases demonstrated the ways individuals construct their own work-related learning spaces, which enables them to work and learn within self-created environments. The individual approaches towards constructing learning environments require both personal creativity and proactivity, as individuals develop their spaces. Furthermore, recognising the potential strengths and limitations of self-created learning spaces makes this process reflective. Case 1 indicates that extending workplace learning 
spaces to other types of environments (such as a home office) is associated with both benefits and shortcomings. The environmental dimension (home environment) overlaps with the individual dimension, resulting in the development of a workplace space that enables an IT specialist to work according to their own agenda and goals at a time and place they consider convenient and productive. At the same time the boundary between home and work space becomes somewhat blurry, which might result in working long hours, as this type of environment would be strongly associated with being in the workplace. Another implication of the 'working at home office' is that of potential isolation and lack of interaction with colleagues. Case 1 indicates that a range of approaches can be employed to tackle these problems, for example through using modern technologies. Case 2 provides an illustration of creating a learning space in an institutional setting through interactions with colleagues. For the IT tutor working in a college of further education, the learning space at work is perceived as an environment that allows for social and professional interaction. Learning through interaction and sharing resources is a significant element of the meaningful learning space at work. Within institutional settings, which might be restrictive to some extent, the learning space is constructed through dialogue, sharing and learning from each other. Case 3 offers an illustrative example of developing and using non-conventional learning spaces. The researcher's case suggests that working and learning 'on the go' could be as productive as working and learning in a more traditional learning environment. The case also indicates that this type of learning space needs to be adapted to the specific working and learning purposes and requirements. The environmental aspect (e.g. being on a bus vs riding a bike) presupposes types of learning activities that an individual might engage in.

\section{Working spaces: modern technologies and virtual learning}

One configuration of the environmental scale has been associated with the development of modern technologies that allows learners to extend their learning spaces to a variety of environments, including home and workplace settings. The expansion of digital technologies provides learners with opportunities to access and undertake learning activities in a range of other settings, including home and workplace environments, public libraries and youth centres, and even on trains and buses. Felstead and Jewson (2012) observe that the recent developments in information technology have weakened the spatial fix, with workers becoming increasingly detached from personal cubes of space. The use of devices such as computers, laptops, mobile phones and netbooks has contributed to the development 
of the virtual learning space where learning might not be associated with a specific site or specific time. The virtual learning environment provides a degree of flexibility for the learner, enabling them to acquire learning at a time and place convenient for them. As indicated by a university researcher, the use of computers and internet enables her to extend her personal workplace learning space to other types of environments (such as home), where the boundaries between different spaces are considerably blurred:

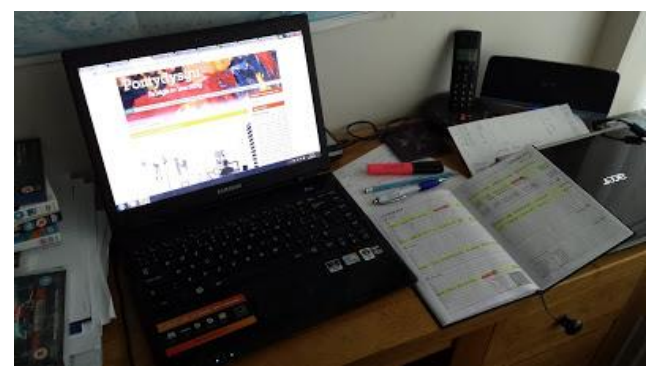

For me, my working space has always been my learning space (well, ever since I became involved in education anyway). This is because I consider myself to be a professional learner. I get paid to teach and research at [a University] but this all comes about through my own personal learning. Also, I do a lot of my work from home, because, although I have wonderful colleagues who are an absolute pleasure to work with, we have a shared space for 5 desks in my office, and it's not always easy to concentrate when there are several of us in the same space, all holding different conversations. [interview with a university researcher]

The use of new technologies has been gradually changing approaches to and ways of teaching and learning in work-related environments. The research by Dennen and Wang (2002) shows how the learning process, which may include interventions such as coaching, mentoring and communities of practice, can be enhanced by the availability of internet-based technologies and present some of the advantages for both the informal learner and the workplace by this technology, as well as the challenges of using the technology well to support informal learning processes. García-Peñalvo et al (2012) also argue that the Internet and its increasing usage has changed informal learning in the workplace specifically stressing the significance of the internet as a new way for people to communicate, where communication is a means of transformation and knowledge exchange. In this context the concept of mobile learning has been further emphasised. However, as Pachler et al (2011) 
further stress, mobile learning is not simply about delivering content to mobile devices but, instead, about the processes of coming to know and being able to operate successfully in and across new and ever-changing contexts and learning spaces. The development of modern technologies plays a central role in changing the perceptions and boundaries of the learning space. Cases 1 and 2, for example, suggest that digital technologies make it possible to extend workplaces and learning spaces to other less conventional environments such as home environments and 'learning on the go' contexts, allowing individuals to work, learn and interact with colleagues:

With new technologies, many conversations take place today over the internet. And those technologies help us develop and curate Personal Learning Networks. Yet face to face conversations can be more animated informal and allow wider ranging conversations. It is notable that many people say the best learning at conferences and meetings take place in the coffee breaks and in the evenings. Sometimes I contact people in advance to meet up for a chat. Other times such meetings happen by chance. Sometimes meetings are with friends I have met and worked with before, sometimes with more distant contacts. And sometimes they are with friends and family through internet and other means of communication. [interview with an independent IT consultant]

Similarly, sharing resources, as in the context of Case 2, takes place through both verbal and online interaction. Online methods of communications, knowledge sharing and development of skills provide flexible opportunities for teaching and learning, interaction and professional and personal development. As illustrated by an IT teacher, online resources are crucial for both facilitating teaching and for teacher professional development and self-learning in the context of further education:

There are always students who are very weak academically and I spend half my time trying to teach, find methods for getting them to be much more academic in how they work. So for example now I don't do the chalk and talk because they just don't listen, just don't listen, so I give them all the answers, and all the questions and all the answers are up there on Moodle. [interview with an IT college tutor]

Discussing own professional development in the context of institutional settings, which might be perceived as restrictive, the tutor emphasised the significant role of modern technologies: 
I bought one book this year, and then I went and asked my line manager for some more. [...] I said 'can we get some more books', she said 'oh OK'. So she spoke to the PA who was sitting beside her and said 'how much have we got in the budget', she said ' $₫ 3$ or $£ 4$ '. OK. So I guess my learning's going to be online!. [interview with an IT college tutor]

The cases indicate that the virtual learning environment provides a degree of flexibility for both professional and personal development, enabling employees to acquire learning and develop skills within a range of environments and settings.

\section{New spaces - new skills}

New spaces of work and learning, and their different configurations, place new demands on skills acquisition and development. The interplay between learning and working spaces, which have been characterised by blurred boundaries, requires employees to develop a range of transferable skills that would enable them to adapt to the changing nature of the learning space at work (Kersh, 2015). The debate on work-related competences has highlighted the issue of the significance of developing personal competences and abilities that people can use in a variety of settings, including workplace settings (Evans et al, 2006; Eraut, 2004). The definition of the term 'competence' offered by Eraut and Hirsh (2007), quoted above, emphasises the important links between individuals' capabilities and their competences. All their competences will be, as Eraut and Hirsh (2007) explain, within their capability; but not all their capability will be needed for any specific job. Therefore, they will also have additional capability, which may have a tacit dimension. Such additional capabilities may be helpful both in enhancing one's competences through further learning (Eraut and Hirsh, 2007) and in facilitating the process of transferability of competences between various contexts and settings. Boud and Garrick (1999: 1) similarly observe that employees are extending their educational capabilities in learning through their work: 'opportunities and problems within work are creating the need for new knowledge and understanding. Employees develop skills of expression and communication which spill over into their personal lives. They learn new ways of collaboration and planning which they apply in their families and community organisations to which they belong.' As Felstead and Jewson (2012) point out, a common set of skills characterises those who successfully adapt to a range of new working spaces. These include, for example, motivation, self-discipline, the ability to establish and maintain boundaries with others to achieve targets without immediate supervision etc. 
In terms of developing skills that enable individuals to navigate a range of spaces and environments, our interviews have indicated the significance of taking into consideration not only space but also time, as another dimension of learning. One of the respondents, reflecting on the role of the time factor, makes a connection between time and space:

Like many, I am a terrible procrastinator, and I do my best work against hard deadlines. That often means working late into the night. As a student I never started studying before 10pm - my studying was soundtracked by John Peel - and I still feel this is when I am at my most focused. I can use late night sessions to finish work, but also to break the back of a problem - so that I can be in control of timescales further down the line.

The interplay between time and space indicates their strong connection between the purposes of space and time management. Self-created learning spaces are often constructed to make the use of time more efficient (e.g. learning/working on the go or working from home). Time management in an appropriate learning and working space is one of the skills required by the modern workplace.

The acquisition of such skills, as Felstead and Jewson (2012: 155) point out, represents a major contribution to underlying learning dispositions of employees, as new spaces of work demand new models of self-governance and time management. For example, international learning spaces, facilitated through transnational projects, are becoming increasingly recognised as learning spaces that provide a shared platform for international development and exchange of ideas and experiences. Such spaces may be developed as both online platforms and face-to-face workshops or any other forms of transnational cooperation. The quotation below illustrates an example of developing a learning space through a project of EU cooperation, specifically describing an instance of presenting the project's developments and findings at a stand at an international conference:

In a big project like Learning layers which has some 20 partners and is organised in different work teams developing different applications to support informal learning, it means you have to appreciate and understand the work of others in order to explain it to visitors. And with the barcamp and posters sessions [at an international conference] we developed spaces for informal learning within the conference. The bar camp - an unconference session - allowed participants to put forward their own ideas for discussions and exploration in a series of round tables. Participants were active and motivated, unlike the usually passive engagement in formal 
paper sessions at conferences. I have little experience in medical education. Most of the participants were practitioners in medical education, with many ideas to learn from. I do not really understand why more such sessions are not organised in major conferences. As an aside, conference venues are seldom designed as learning spaces. Rows of chairs facing a presenter at the front hardly inspires interaction and social learning. [...] But for me the real learning at the conference was from the Learning Layers team. There were eight of us and we rotated in pairs on the exhibition stand. Like many of the big European research projects, Learning Layers in an interdisciplinary project. Partners include social scientists, pedagogists, business science specialists, designers and technical developers. We can learn from each other and from people with a different subject specialism from our own. This happens to an extent in formal project meetings but the time spent on the stand allowed more in depth conversations. And in the course of the three days spent together we bonded as a team. [extract from interview with an independent IT consultant]

Learning and sharing knowledge internationally is one of the central implications of international learning spaces in the globalised environment. The contemporary debate has highlighted the significance of transferrable skills that enable individuals to navigate a range of spaces both national and international.

The discussion on understanding work-related transferrable skills required by new workspaces has underlined the importance of gaining a better understanding of how knowledge and competences are used and developed as people move between different contexts and settings, including both workplace and other informal/formal settings. While the metaphor of 'transfer' has been dominant in recent times, the current debate has extensively problematised this notion, which often pays insufficient attention to the processes involved in recontextualising skills and knowledge in order to put them to work in new and changing contexts (see Hager and Hodkinson, 2011; Evans and Guile, 2012). In this context, the role played by tacit skills as well as interdependencies and interplay between tacit and explicit dimensions at work have been identified as factors affecting the transferability and use of skills and competences in a range of settings and spaces. 


\section{Conclusion}

Complex interdependencies between learning, work and space have contributed to the emergence of new workspaces, where the boundaries between work and learning are considerably blurred. The cases, considered in this article, indicated that the learning space at work can be perceived as a combination or overlap of a range of components, such as physical space, learning contexts and environments, formal/informal learning and virtual learning. Research (e.g. Brooks et al, 2012) suggests that the spatial dimensions of workplace learning play a significant role in facilitating or undermining employees' opportunities for professional development as well as their outcomes and motivations towards the acquisition of a range of skills and development of social practices, that facilitate communication, knowledge sharing and skills development.

Methodological challenges in researching the ways in which workplaces are experienced as learning spaces have been addressed using the photo-participatory method. The method has enabled practitioners to articulate what a learning space means for them, in ways that entail visualisation and reflection. The approach has readily engaged the participation of busy practitioners who might otherwise have declined a research interview about a seemingly abstract concept. The cases have represented the participant's voice and the researcher analyses have been dedicated to interpreting what the teller means, in the context of relationship between the teller, the photograph and the audience. The method has enabled comparisons to be drawn between the learning spaces of practitioners who inhabit an institutional environment and those who work independently. A wider aim of the photoparticipatory method has been to enable particular cases to be shared, in the context of the international project, in ways that facilitate international debate on the meanings and dimensions of learning spaces in contrasting cultural contexts.

The use of the photo-participatory interviews with IT professionals has helped to illuminate how:

- Workplace spaces can provide continuous opportunities for learning;

- Employees as well as students learn through a range of learning spaces in the working environment;

- Learning spaces are co- constructed; 
- Different types of learning are interrelated, and this interrelation may facilitate or undermine learning processes and outcomes;

- Modern technologies can play a significant role in enabling individuals to navigate a range of spaces.

The research has suggested that different types of learning spaces, (e.g. institutional vs independent sector settings) may play a significant part in enhancing the learning processes and aspirations of employees within their workplaces. Considering views and perspectives from both independent specialists and institutional teachers and researchers enables us to reflect on how the concept of space is exercised in institutional vs independent workplace settings. The data suggest that in both types of settings individuals learn through a variety of spaces, including self-created learning spaces. However, the independent sector as opposed to the institutional sector, offers more flexibility in terms of creating and developing less conventional learning and working spaces, which sometimes stretches beyond the boundaries of a single country (e.g. Case 1). Therefore, in the context of independent sectors, in which the boundaries between institutional and environmental scales are blurry, workers generate their own institutional environment. Institutional settings allow some flexibility for creating personal learning spaces; however, only within the boundaries of the specific workplace (institution). Digital technologies in both independent and institutional sectors further play a significant role in expanding and developing virtual learnings spaces, which facilitate communication, knowledge sharing and skills development.

Developing both confidence and motivation in the workplace is another significant outcome associated with different learning spaces. Both the literature review and our interviews have suggested that practitioners' capabilities and motivations have developed in a range of workplaces related to a wider range of differing environments. Apart from using their newly acquired skills in the workplace, their capabilities are readily recontextualised to mesosystems, for example their family environments. The data suggest that different types of learning are interrelated, and this interrelation may facilitate or undermine learning processes and outcomes. Family settings provide opportunities for employing and developing a range of skills acquired in the course of workplace literacy and numeracy programmes, thus extending the learning space from the workplace to the home environment. The concept of virtual learning that has been associated with the expansion of digital technologies broadens the notion of the learning space, and contributes to erasing the borders between different types of learning site. In order to 
be able to navigate different social landscapes and spaces, individuals need to develop a range of transferable skills that enable them to navigate the changing demands of workspaces, and more broadly, the changing requirements of labour markets.

The consideration of workplace learning and its different configurations has underpinned the complexities between work, learning, agency and space. The interdependencies between individual engagement, competence development and organisational context strongly relate to workplace social practices and the ways they reflect and shape culture and social structures including work organisations (Chisholm et al, 2012). The complexities of workplace learning have been reflected in the changing requirements for competence development and its interplay with the changing nature of the learning space at work. The exercise of agency through the virtual environment has the potential to facilitate learning at work, relating it to other spaces and environments. The perspective of social ecology provides a way into understanding the complexities of factors that impact on learning in the workplace, through the interplay of actors, structures, processes and environments. This interplay is not restricted to the workplace but involves the overlap of learning spaces and other contexts that extend way beyond the workplace. The concept of learning in, for and through the workplace (Evans et al., 2006) thus attends to the social processes that shape employees' perceptions and attitudes towards engagement in workplace learning, thus influencing their professional and personal development and life chances within the workplace and beyond. 


\section{References}

Bronfenbrenner, U. (1977) Toward an experimental ecology of human development, American Psychologist, July: 513-530

Bronfenbrenner, U. (1979) The ecology of human development: experiments by nature and design. Cambridge, Harvard University Press.

Brooks et al. eds (2012) Changing Spaces of Education: New Perspectives on the Nature of Learning. Routledge.

Chen, Cheng and Wen, Peng (2011). New Generation Employees' Learning Willingness and Mentors' Knowledge Sharing Behavior. Economic Management, (10), 87-93.

Chisholm, L., Lunardon, K., Ostendorf, A. and Pasqualioni, P (Eds.) (2012). Decoding the meaning of learning at work in Asia and Europe. Innsbruck university press.

Dennen V.P. and Wang, M (2002). The Keyboard-Based Job Coach: Informal Learning via the Internet. In: Advances in Developing Human Resources 20024 : 440.

Edwards, R., Gallagher J. and Whittaker, S. eds (2004) Learning Outside the Academy: International research perspectives on lifelong learning. London, Routledge.

Eraut, M. 2004. Informal learning in the workplace. Studies in Continuing Education 26 (2): 247-273

Eraut, M. and Hirsh, W. (2007) The Significance of Workplace Learning for Individuals, Groups and Organisations, SCOPE, http://www.skope.ox.ac.uk/publications/significance-workplace-learning individuals-groups and-organisations

Evans, K., Hodkinson, P., Rainbird, H. and Unwin, L. (2006) Improving workplace learning. New York: Routledge

Evans, K. (2009) Learning, Work and Social Responsibility. Springer: Dordrecht

Evans, K., Hodkinson, P., Rainbird, H. and Unwin, L. (2006) Improving workplace learning. New York: Routledge

Evans K. and Guile, D. (2012) Putting different forms of knowledge to work in practice. In: J. Higgs et al., (eds.), Practice-Based Education: Perspectives and Strategies, Sense Publishers, Rotterdam: 113-130

Evans, K. and Kersh, N. (2014) Training and Workplace Learning, in K. Kraiger, J. Passmore, N. R. Santos, S. Malvezzi (Eds.), The Wiley-Blackwell Handbook of The Psychology of Training, Development and Performance Improvement. Chichester, pp. 356-370

Evans K. and Kersh N. (2017-forthcoming) Competence Development and Workplace Learning: Enduring Challenges in the Interplay of Policy and 
Practice in the UK, in Mulder, $M$ (ed.) Competence-based Vocational and Professional Education, Volume 23 of the series Technical and Vocational Education and Training: Issues, Concerns and Prospects pp. 317-335.

Felstead, A. and Jewson, N. (2012) New places of work, new spaces of learning. In: Brooks et al (eds) 'Changing Spaces of Education: New Perspectives on the Nature of Learning. Routledge: 137-158

Foucault, M. (1980) Power/Knowledge. Selected Interviews and Other Writings 1972-1977. New York: Pantheon.

Fuller, A., Unwin, L., Felstead, A., Jewson, N. and Kakavelakis, K. (2007) Creating and using knowledge: an analysis of the differentiated nature of workplace learning environments. British Educational Research Journal, 33 (5): 743-759

García-Peñalvo, Francisco J., Ricardo Colomo-Palacios and Miltiadis D. Lytras (2012). Informal learning in work environments: training with the Social Web in the workplace. In: Behaviour \& Information Technology, 31:8, pp. 753-755.

Goffman, E. (1990) The Presentation of Self in Everyday Life. Penguin Books.

Guile, D. (2010a) Learning to work in the creative and cultural sector: new spaces, pedagogies and expertise; Journal of Education Policy, 25 (4): 465-484

Guile, D. (2010b). The learning challenge of the knowledge economy. Rotterdam: Sense

Hager, P. and Hodkinson, P. (2009) Moving beyond the metaphor of transfer of learning British Educational Research Journal, 5, 4 : 619-638

Heiskanen, T. and Heiskanen, H (2011) Spaces of innovation: experiences from two small high-tech firms, Journal of Workplace Learning, 23 (2): 97 - 116.

Hodkinson, P. and Bloomer, M. (2002) Learning careers: conceptualising lifelong work-based learning. In: K. Evans et al. (eds) Working to Learn - Transforming Learning in the Workplace. London, Kogan Page Limited: 29-43

Kersh, N., Evans, K and Kontiainen. S (2011) Use of conceptual models in selfevaluation of personal competences in learning and in planning for change, International Journal of Training and Development, 15, 4: 290-305

Kersh, N., Waite E. and Evans K (2012) The Spatial Dimensions of Workplace Learning: Acquiring Literacy and Numeracy Skills within the Workplace. In: $R$. Brooks et al (eds) Changing Spaces of Education: New Perspectives on the Nature of Learning, Routledge: 182-204

Kersh, N. (2015). Rethinking the learning space at work and beyond: The achievement of agency across the boundaries of work-related spaces and environments. International Review of Education, 61 (6), 835-851.

Kohlegger, M., Maier, R. and Remus, U. (2013). Freedom of choice: perspectives on personal workplaces. ECIS 2013 Proceedings.

Kolb, D.A. (1984) Experiential Learning, Englewood Cliffs, NJ: Prentice Hall. 
Kolb, A. and Kolb, D. (2005) Learning styles and learning spaces: enhancing experiential learning in higher education, Academy of Management Learning and Education, 4, 2: 193-212.

Malloch, M., Cairns, L., Evans, K and O'Connor, B., eds. (2011) The Sage Handbook of Workplace Learning, London, Sage.

Nonaka, I. and Takeuchi, H. (1995) Thę Knowledge Creating Company. New York: Oxford University Press.

Pachler, N., Pimmer, C. and Seipold, J. eds (2011) Work-based mobile learning: concepts and cases. Oxford: Peter Lang.

Rauner F. and Smith, E (eds) (2010) Rediscovering Apprenticeship, Dordrecht: Springer.

Remedios, R. and Boreham, N. (2004) Organisational learning and employees' intrinsic motivation, Journal of Education and Work, 17:2: 219-235

Soja, E. (2002) Postmetropolis, Critical Studies of Cities and Regions, 4th edn, Blackwell Publishing.

Solomon, N., Boud, D. and Rooney, D. (2006) The in-between: exposing everyday learning at work, International Journal of Lifelong Education, 25, 1: 3-13 